\title{
A Double-Blind, Controlled Evaluation of the Value of Sarapin in NeUral Blockade
}

\author{
Kavita N. Manchikanti, Vidyasagar Pampati, MSc, Kim S. Damron, RN, and Carla D. McManus, RN, BSN
}

\begin{abstract}
Objective: To demonstrate the effectiveness of Sarapin in prolonging the action of neural blockade with improved pain relief.

Design: Prospective, continuous, double-blind trial including 500 consecutive patients undergoing either caudal epidural injections; cervical, thoracic, lumbosacral facet joint nerve blocks; and/or intercostal nerve blocks or a combination thereof.

Background: Sarapin has been reported as an agent to provide pain relief without motor weakness with an excellent risk/ benefit ratio in neural blockade. Sarapin is a suspension of powdered Sarracenia purpurin (pitcher plant) in alkaline solution. Researchers theorize that the distillate contained an unidentified biological substance that potentiates the action of the ammonium ion. Modest but significant benefits were demon-
\end{abstract}

Multiple therapeutic agents utilized in neural blockade include local anesthetics, steroids, neurolytic agents, and Sarapin ${ }^{\circledR}$. Much has been written about local anesthetics, steroids, and neurolytic agents. However, there is paucity of literature on the effectiveness of Sarapin in neural blockade. The value of Sarapin in relieving pain of neurologic origin was reported by Bates and Judovich in 1931 (1, 2). Sarapin has been reported to cause no motor weakness following injection of the peripheral nerve or to effect loss of touch, pressure, pinprick, or temperature sensibility. Sarapin has been claimed to have excellent risk/benefit ratio. Controlled studies with procaine, saline, and water showed prolongation of the duration of effect in favor of Sarapin (2). Sarapin is a suspension

From Pain Management Center of Paducah, Paducah, KY. Address Correspondence: Vidyasagar Pampati, 2831 Lone Oak Road, Paducah, KY-42003. E-mail: sagar@thepainmd.com

Funding: There was no external funding in preparation of this manuscript.

Conflict of Interest: None strated with diagnostic blocks, with diagnostic lumbar medial branch blocks, therapeutic lumbar medial branch blocks, and caudal epidural injections. In an experimental study in the horse, no benefits were seen by injection of Sarapin. The authors proposed that there may not be any benefits in other species as well. Multiple therapeutic agents utilized in neural blockade, including local anesthetics, steroids, and neurolytic agents, have been evaluated extensively. Sarapin has not been evaluated in controlled trials.

Methods: Five hundred consecutive patients undergoing either caudal epidural injections; cervical, thoracic, or lumbosacral facet joint nerve blocks; or intercostal nerve blocks or a combination thereof were included in the study. Each patient was treated with two blocks. The treatments were dou- ble-blind and prospective. Each patient acted as their own control.

Results: The results showed that 500 patients received a total of 828 treatments, once with Sarapin and once without. There were no significant differences between these groups, either with pain relief measured by numeric pain scale or duration of significant relief defined as $50 \%$ or greater relief.

Conclusion: This prospective, doubleblind trial of 500 patients undergoing 828 treatments, one time with Sarapin and a subsequent time without, with each patient acting as their own control, showed no significant differences in the pain relief or duration of significant relief with the addition of Sarapin.

Keywords: Neural blockade, therapeutic agents, Sarapin, local anesthetic, steroids of powdered Sarracenia purpurin (pitcher plant) in alkaline solution. The basis of the pitcher plant derivative, or Sarapin, was explained by experiments performed on the action potentials of the saphenous nerve of the cat, which showed that the C-fiber potential was completely obliterated by pitcher-plant extract after immersion in the solution for about 5 minutes. Researchers theorized that the distillate contained an unidentified biological substance that potentiates the action of the ammonium ion $(1,2)$. Modest but significant benefits were demonstrated with diagnostic lumbar medial blocks utilizing Sarapin, which provided not only diagnostic validity, but also therapeutic value (3). Modest therapeutic effect was reported with Sarapin when utilized in lumbar medial branch blocks, which was similar to the relief seen with a mixture of local anesthetic and methylprednisolone (4). It was also concluded that caudal epidural injections with steroids or Sarapin were equally effective in managing chronic, persistent low back pain (5). In contrast, it was demonstrat- ed that Sarapin has no significant classic or local anesthetic actions in the horse, and probably not in other species as well (6).

Interventional techniques utilizing various drugs are one of the common modalities of treatments utilized in managing chronic pain (7). Injection of local anesthetics and steroids into the epidural space to provide neural blockade have been evaluated extensively. In contrast, evidence for Sarapin is lacking as its effectiveness has not been evaluated independently without multiple variables in a controlled fashion.

Hence, this controlled evaluation was designed and undertaken to evaluate the role of Sarapin in prolonging the action of local anesthetic in various types of interventional techniques, including caudal epidural injections; cervical, thoracic, and lumbosacral facet joint nerve blocks; and intercostal nerve blocks. The objective of this evaluation was to evaluate prolongation of the relief of a nerve block or epidural injection with local anesthetic with or without Sarapin in a prospective double-blind manner. 


\section{Methods}

This study included 500 consecutive patients undergoing either caudal epidural injections; cervical, thoracic, or lumbosacral facet joint nerve blocks; intercostal nerve blocks, or a combination thereof. The study protocol met the Institutional Review Board criteria. Inclusion criteria included all the patients consenting to undergo the procedure who have been stable in the interventional pain management program for at least 12 months and steadily have experienced relief of 2 to 4 months. Exclusion criteria included patients with less than 2 months of relief or more than 6 months of relief and patients unable to understand the consent.

All the patients received two consecutive blocks with or without Sarapin without any other variables. Local anesthetic and steroid remained the same. The treatments were double-blind and prospective. Neither the treating physician nor the patient were aware of addition or lack thereof of Sarapin to their treatment.

The evaluation included data collection as to the variables of age, gender, duration of pain in months, mode of onset of pain, height, and weight. The quality of pain relief was characterized as less than $50 \%$ relief, or greater than $50 \%$ relief. Pain relief greater than $50 \%$ was considered significant. Baseline pain rating was obtained from average pain rating provided on admission based on numeric pain rating scale. Numeric pain rating scale was assessed, along with significant pain relief, following both injections in each patient by one of the investigators not participating in the study.

All procedures were performed by one physician in an ambulatory surgery setting in a sterile operating room. All injections were performed under fluoroscopy, with patients in the prone posi- tion, under appropriate monitoring with intravenous access and mild sedation with midazolam and fentanyl. Following the blocks, the patients were discharged home. Upon a return visit, each patient was evaluated for the amount of pain relief on the basis of numeric pain rating scale, and perceived significant pain relief of $50 \%$ or greater and its duration.

Data were recorded on a database using Microsoft ${ }^{\circledR}$ Access ${ }^{\circledR}$. The SPSS version 9.0 statistical package was used to generate frequency tables, and the chisquared statistic was used to test the significant difference between two treatments. Fisher's Exact test was used wherever expected value was less than five. Student's t-test was used to test mean difference between groups. Results were considered statistically significant if the $P$-value was less than 0.05 .

\section{Results}

\section{Patient Characteristics}

Demographic data are illustrated in Table 1.

Procedural characteristics are illustrated in Table 2. Five hundred patients underwent 828 treatments, each on two occasions.

\section{Pain Relief}

Table 3 shows significant relief with injection. There was no significant difference noted with or without Sarapin. Significant relief ranged from $11.2 \pm 3.4$ to $12.4 \pm 1.63$ weeks

Table 3 also illustrates numeric pain scale baseline compared to with or without Sarapin. There were no significant differences noted between the groups.

\section{Discussion}

The results of this prospective, double-blind evaluation showed no signifi- cant difference with addition of Sarapin in the pain rating or the duration of significant pain relief as defined by $50 \%$ or greater relief. These results are in contrast to previous evaluations by various authors including the present authors (15). However, these results do correlate with a recent report demonstrating that Sarapin has no significant classic or local anesthetic action in the horse (6). These results also showed average pain relief either with caudal, facet joint blocks, or intercostal nerve blocks to range from 11.2 \pm 3.4 weeks to $12.4 \pm 1.63$ weeks with no significant differences noted with or without Sarapin. The study also demonstrated significant reduction in the pain scale with treatment with or without Sarapin.

Corticosteroids have been used since 1952 in the management of chronic pain (8). The rationale for steroid usage in neural blockade is primarily based on the benefits of neural blockade, including the pain relief which outlasts by hours, days, and sometimes weeks, the transient pharmacologic action of other adjuvant agents such as local anesthetics and others. While there are no clear-cut explanations for these benefits available currently, it is believed that neural blockade alters or interrupts nociceptive input, reflex mechanisms of the afferent limb, self-sustaining activity of the neuron pools and neuraxis, and the pattern of central neuronal activities (9). Corticosteroids also reduce inflammation either by inhibiting the synthesis or release of a number of pro-inflammatory substances (10). Various modes of action of corticosteroids include membrane stabilization; inhibition of neural peptide synthesis or action; blockade of phospholipase A2 activity; prolonged suppression of ongoing neuronal discharge; suppression of sensitization of dorsal horn neurons; and re-

Table 1. Demographic characteristics

\begin{tabular}{|l|l|c|}
\hline \multirow{2}{*}{ Gender } & Male & $35 \%(174)$ \\
\cline { 2 - 3 } & Female & $65 \%(326)$ \\
\hline Age in years & Mean \pm SD & $49 \pm 12.3$ \\
\hline Weight in pounds & Mean \pm SD & $180 \pm 48.5$ \\
\hline Height in inches & Mean \pm SD & $66.5 \pm 3.95$ \\
\hline Duration of the pain (months) & Mean \pm SD & $152 \pm 116.4$ \\
\hline \multirow{2}{*}{ Mode of onset of the pain } & Gradual & $41 \%(207)$ \\
\cline { 2 - 3 } & Following an Incident & $59 \%(293)$ \\
\hline
\end{tabular}


Table 2. Procedure characteristics

\begin{tabular}{|l|c|c|c|c|}
\hline & Right & Left & Bilateral & Total \\
\hline Cervical facet joint nerve blocks & $17 \%(59)$ & $21 \%(73)$ & $62 \%(220)$ & 352 \\
\hline Thoracic facet joint nerve blocks & $19 \%(10)$ & $19 \%(10)$ & $62 \%(33)$ & 53 \\
\hline Lumbar facet joint nerve blocks & $13 \%(25)$ & $10 \%(20)$ & $77 \%(154)$ & 199 \\
\hline Intercostal nerve blocks & $19 \%(11)$ & $21 \%(12)$ & $60 \%(35)$ & 58 \\
\hline Caudal epidural & \multicolumn{3}{|l|}{ Total Procedures } & 828 \\
\hline \multicolumn{5}{|r|}{}
\end{tabular}

Table 3. Amount of duration of pain relief with neural blockade with or without Sarapin

\begin{tabular}{|l|c|c|c|c|c|}
\hline \multirow{2}{*}{ Nerve Blocks } & \multicolumn{3}{|c|}{ Average Pain Score } & \multicolumn{3}{c|}{ Pain Relief (wks) } \\
\cline { 2 - 6 } & Baseline & $\begin{array}{c}\text { With Sarapin } \\
\text { Treatment }\end{array}$ & $\begin{array}{c}\text { Without Sarapin } \\
\text { Treatment }\end{array}$ & $\begin{array}{c}\text { With Sarapin } \\
\text { Treatment }\end{array}$ & $\begin{array}{c}\text { Without Sarapin } \\
\text { Treatment }\end{array}$ \\
\hline Cervical facet joint nerve blocks (352) & $7.90 \pm 0.95$ & $3.42^{\star} \pm 0.61$ & $3.44^{\star} \pm 0.69$ & $12.2 \pm 2.1$ & $12.0 \pm 2.5$ \\
\hline Thoracic facet joint nerve blocks (53) & $7.68 \pm 0.94$ & $3.30^{\star} \pm 0.57$ & $3.45^{\star} \pm 0.75$ & $11.6 \pm 2.7$ & $11.2 \pm 3.4$ \\
\hline Lumbar facet joint nerve blocks (199) & $7.92 \pm 0.95$ & $3.39^{\star} \pm 0.66$ & $3.46^{\star} \pm 0.73$ & $11.9 \pm 2.47$ & $11.6 \pm 2.74$ \\
\hline Intercostal nerve blocks (58) & $7.79 \pm 0.69$ & $3.45^{\star} \pm 0.60$ & $3.34^{\star} \pm 0.48$ & $12.4 \pm 1.63$ & $12.3 \pm 1.76$ \\
\hline Caudal epidural (166) & $7.95 \pm 0.89$ & $3.53^{\star} \pm 0.72$ & $3.62^{\star} \pm 0.83$ & $11.8 \pm 2.3$ & $11.6 \pm 2.58$ \\
\hline
\end{tabular}

* Indicates significant difference with Baseline values

versible local anesthetic effect (10). Thus far, the scientific basis of some of these concepts, at least in part, is proven for spinal pain management with epidural injections of betamethasone and for methylprednisolone (11-16).

The suppression of neuronal transmission is a key mechanism by which local anesthetics achieve their clinical effect. Thus, local anesthetics are used for their ability to inhibit the propagation of the action potential (17). Researchers also have reported the anti-inflammatory properties of anesthetic agents with possible mechanisms including inhibition of phagocytosis, inhibition of phagocyte oxygen consumption, reduction of polymorphonucleocyte lysosomal enzyme release, and decrease of superoxide anion production, and reversible inhibition of granulocyte adherence (1827). Another proposed mechanism for the therapeutic effect of local anesthetic is the restoration of blood flow. In an animal model, it was found that local anesthetic agents with nerve root infiltration or sympathetic ganglion blocks increased intra-radicular flow (28). Based on this, increase in blood flow has been considered as a therapeutic mechanism for local anesthetic action as diminished blood flow has been hypothesized causing pain in spinal stenosis and herniated nucleus pulposus (29-31). Some in- vestigators also have suggested that the therapeutic effect may be mediated by the inhibition of sympathetic output (32, 33). Further, central processing theories also have been postulated to explain the therapeutic effect of local anesthetics ( 9 , $34)$. Based on this theory, local anesthetic agents may cause a temporary block of the pain cycle established in the brain, or repetitive firing nerves of the wide dynamic type neurons have been triggered in the spinal cord (34).

In contrast, no such explanations exist for Sarapin. Sarapin is a suspension of powdered Sarracenia purpurin (pitcher plant) in alkaline solution. The value of Sarapin in relieving pain of neurological origin was based on clinical investigations of 1931 indicating its pain relief activity and an excellent risk/benefit ratio without compromising motor function, touch, pressure, pinprick or temperature sensibility $(1,2)$. It was theorized that Sarapin suppressed or even obliterated the C-fiber potential. The activity was attributed to an unidentified biological substance that potentiated the action of the ammonium ion. Thus, there are no scientific or experimental evaluations either in animals or humans elucidating the effectiveness of Sarapin except for one negative report (6).

This is a double-blind trial with the same patients acting as controls. This also includes a large number of patients undergoing even a greater number of procedures. The number of procedures ranged from a low of 53 for thoracic facet joint nerve blocks to a high of 352 for cervical facet joint nerve blocks. We may be criticized for not randomizing. However, it was felt that consecutive sample was more effective and there is no better way than using the patients as their own controls. Thus, this study shows significant results that Sarapin, either in nerve blocks or in caudal epidural injection fails to provide any additional relief than provided by local anesthetic and steroids. There were no complications noted, thus, Sarapin is a safe agent.

\section{Conclusion}

The results of this prospective, double-blind evaluation of 500 consecutive patients undergoing 828 procedures on two occasions, with or without Sarapin, showed no significant improvement with the addition of Sarapin, either in pain relief or the duration of significant pain relief.

\section{ACKNOWLEDGMENTS}

The authors wish to thank Tonie Hatton, transcriptionist; and Marla K. Neihoff and Lorie A. Caldwell, medical records coordinators; for their assistance in preparation of this manuscript. 


\begin{tabular}{|l|}
\hline Author Affiliation: \\
Kavita N. Manchikanti \\
Research Assistant \\
Pain Management Center of \\
Paducah \\
2831 Lone Oak Road \\
Paducah, Kentucky-42003 \\
Vidyasagar Pampati, MSc \\
Statistician \\
Pain Management Center of \\
Paducah \\
2831 Lone Oak Road \\
Paducah, Kentucky 42003 \\
E-mail sagar@thepainmd.com \\
Kim S. Damron, RN \\
Clinical Coordinator \\
Pain Management Center of \\
Paducah \\
2831 Lone Oak Road \\
Paducah, Kentucky 42003 \\
E-mail: kim@thepainmd.com \\
Carla D. McManus, RN, BSN \\
Clinical Coordinator \\
Pain Management Center of \\
Paducah \\
2831 Lone Oak Road \\
Paducah, Kentucky 42003 \\
E-mail: carla@thepainmd.com
\end{tabular}

\section{RefERENCES}

1. Bates W, Judovich BD. Intractable pain. Anesthesiology 1942; 3:663-672.

2. Judovich BD, Bates W. Pain syndromes. Treatment by paravertebral nerve block. Philadelphia, FA Davis, 1950; pp 242-249.

3. Manchikanti L, Pampati VS, Bakhit CE et al. The diagnostic validity and therapeutic value of lumbar facet joint nerve blocks with or without adjuvant agents. Cur Rev Pain 2000; 4:337-344.

4. Manchikanti L, Pampati V, Bakhit CE et al. Effectiveness of lumbar facet joint nerve blocks in chronic low back pain: A randomized clinical trial. Pain Physician 2001; 4: 101-117.

5. Manchikanti L, Pampati V, Rivera J et al. Caudal epidural injections with Sarapin or steroids in chronic low back pain. Pain Physician 2001; 4:322-335.

6. Harkins JD, Mundy GD, Stanley SD et al. Lack of local anesthetic efficacy of Sarapin in the abaxial sesamoid block model. J Vet Pharmacol Ther 1997; 20:229-232.

7. Manchikanti L, Staats P, Singh V et al. Evi- dence-based practice guidelines for interventional techniques in the management of chronic spinal pain. Pain Physician 2003; 6:3-80.

8. Bogduk N, Christophidis N, Cherry D et al. Epidural use of steroids in the management of back pain. Report of working party on epidural use of steroids in the management of back pain. National Health and Medical Research Council. Canberra, Commonwealth of Australia, 1994, pp 1-76.

9. Fox AJ, Melzack R. Transcutaneous electrical stimulation to acupuncture. Comparison of treatment of low back pain. Pain 1976; 2:141-148.

10. Manchikanti L. Role of neuraxial steroids in interventional pain management. Pain Physician 2002; 5:182-199.

11. Olmarker K, Byrod G, Cornefjord M et al. Effects of methylprednisolone on nucleus pulposus-induced nerve root injury. Spine 1994; 19:1803-1808.

12. Hayashi N, Weinstein JN, Meller ST et al. The effect of epidural injection of betamethasone or bupivacaine in a rat model of lumbar radiculopathy. Spine 1998; 23: 877-885.

13. Lee HM, Weinstein JN, Meller ST et al. The role of steroids and their effects on phospholipase $A_{2}$. An animal model of radiculopathy. Spine 1998; 23:1191-1196.

14. Minamide A, Tamaki T, Hashizume $\mathrm{H}$ et al. Effects of steroids and lipopolysaccharide on spontaneous resorption of herniated intervertebral discs. An experience study in the rabbit. Spine 1998; 23:870-876.

15. Kingery WS, Castellote JM, Maze M. Methylprednisolone prevents the development of autotomy and neuropathic edema in rats, but has no effect on nociceptive thresholds. Pain 1999; 80:555-566.

16. Byrod G, Otani K, Brisby H et al. Methylprednisolone reduces the early vascular permeability increase in spinal nerve roots induced by epidural nucleus pulposus application. J Orthop Res 2000; 18:983-987.

17. Raymond SA, Strichartz GR. Further comments on the failure of impulse propagation in nerves marginally blocked by local anesthetics. Anesth Analg 1990;70:121-122.

18. Cullen BF, Haschke RH. Local anesthetic inhibition of phagocytosis and metabolism of human leukocytes. Anesthesiology 1974; 40:142-146.

19. Hoidal JR, White JG, Repine JE. Influence of cationic local anesthetics on the metabolism and ultrastructure of human alveolar macrophages. J Lab Clin Med 1979;93: 857-866.

20. Goldstein IM, Lind S, Hoffstein S et al. In fluence of local anesthetics upon human polymorphonuclear leukocyte function in vitro. J Exp Med 1977; 146:483-494.

21. MacGregor RR, Thorner RE, Wright DM. Lidocaine inhibits granulocyte adherence and prevents granulocyte delivery to inflammatory sites. Blood 1980; 56:203-209.

22. Cassuto J, Nellgard P, Stage L. Amide local anesthetics reduce albumin extravasation in burn injuries. Anesthesiology 1990; 72: 302-307.

23. Peck SL, Johnston RB, Horwitz LD. Reduced neutrophil superoxide anion release after prolonged infusions of lidocaine. J Pharmacol Exp Ther 1985; 235: 418-422.

24. Rimback G, Cassuto J, Wallin $\mathrm{G}$ et al. Inhibition of peritonitis by amide local anesthetics. Anesthesiology 1988; 69:881-886.

25. Martinsson T, Haegerstrand A, Dalsgaard C. Ropivacaine and lidocaine inhibit proliferation of nontransformed cultured adult human fibroblasts, endothelial cells and keratinocytes. Agents Actions 1993; 40: 78-85.

26. Ohsaka A, Saionji D, Sato $\mathrm{N}$ et al. Local anesthetic lidocaine inhibits the effect of granuloctye colony stimulating factor on human neutrophil functions. Exp Hematol 1994; 22:460-466.

27. Ramus GV, Cesano L, Barbalonga A. Different concentrations of local anesthetics have different modes of action on human lymphocytes. Agents Actions 1983;13: 333-341.

28. Yabuki S, Kikuchi S. Nerve root infiltration and sympathetic block. Spine 1995; 20: 901-906.

29. Olmarker K, Rydevik B, Holm S, Bagge U. Effects of experimental graded compression on blood flow in spinal nerve roots. A vital microscopic study on the porcine cauda equina. J Orthop Res 1989; 7:817-823.

30. Takahashi K, Olmarker K, Holm S et al. Double level with continuous monitoring of intraneural blood flow in the porcine cauda equina. J Ortho Res 1993; 11:104-109.

31. Yabuki S, Kikuchi S, Olmarker K. Acute effects of nucleus pulposus on blood flow and endoneurial fluid pressure in rat dorsal root ganglia. Spine 1998; 23:2517-2523.

32. Winne AP, Hartman JT, Myers HL Jr et al. Pain Clinic II: Intradural and extradural corticosteroids for sciatica. Anesth Analg Curr Res 1972; 51:990-1003.

33. El Mahdi MA, Abdel Latif FY, Janko M. The spinal nerve root "innervation" and a new concept of the clinico-pathological interrelations in back pain and sciatica. Neurochirurgia 1981; 24:137-141.

34. Raj PP. Prognostic and therapeutic local anesthetic blockade. In Cousins MJ, Bridenbaugh PO (eds). NeuralBlockade. Lippincott, Philadelphia, 1988. 